\title{
A (IN) EXISTÊNCIA DA SEXUALIDADE NO CURSO DE PEDAGOGIA: O CURRÍCULO OCULTO EM EVIDÊNCIA ${ }^{1}$
}

\author{
Andreza Marques de Castro LEÃO ${ }^{2}$ \\ Paulo Rennes Marçal RIBEIRO ${ }^{3}$
}

RESUMO: O currículo é importante instrumento, por meio do qual são delineados os aspectos principais a serem alcançados no contexto educacional. Ele pode ser real, isto é, ocorrer em sala de aula em decorrência do projeto pedagógico, bem como, ser oculto, sendo transmitido sem ser habitualmente mencionado pelos professores. A sexualidade embora não esteja integrada aos componentes do currículo formal, está presente nos ditos e interditos escolares, na maneira de agir, articular e falar da comunidade escolar, se expressando por meio do currículo oculto. Considerando isso, o presente estudo de natureza qualitativo e quantitativo teve por objetivo analisar a grade curricular de um curso de Pedagogia de uma Universidade Estadual localizada no interior do Estado de São Paulo, assim como, dar voz aos discentes do referido curso a fim de analisar se a sexualidade está presente de forma nítida no currículo formal. Para tanto, foi realizado um estudo documental do referido curso, mais precisamente do seu processo curricular

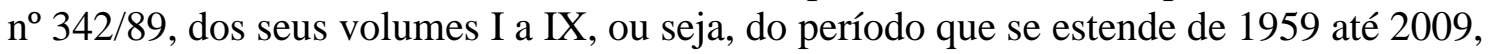
bem como do programa curricular vigente até o ano de 2007. Além disso, empregou-se um questionário fechado contendo 20 questões o qual contou com a participação de 70 alunos de Pedagogia do período diurno e noturno da referida Universidade. Desde o seu curriculum inicial até o mais recente inexiste espaço para disciplinas de sexualidade, sendo que o 'avanço' que pode ser assinalado é a introdução de escassas disciplinas optativas que não mais existem no curso vigente. Nos dizeres da maioria dos discentes, a sexualidade não é um assunto abarcado no mencionado curso. Estes dados mostram que tanto o currículo real quanto o oculto não dão o devido espaço a este tema. Isto posto, é imprescindível que este curso, assim como os diferentes cursos de licenciatura, se atenham a necessidade da sexualidade e da educação sexual fazerem parte da grade curricular real, de maneira a possibilitar aos alunos o acesso a este saber.

PALAVRAS-CHAVE: Currículo. Sexualidade. Educação Sexual. Pedagogia.

\section{Introdução e justificativa}

A escola democratizada deve possibilitar aos alunos o ingresso e, sobretudo, a permanência deles nesta Instituição, de modo que tenham acesso ao saber

\footnotetext{
${ }^{1}$ Artigo elaborado a partir da tese de doutorado da primeira autora sob orientação do segundo autor. Ver: Leão (2009).

2 UNESP - Universidade Estadual Paulista. Faculdade de Ciências e Letras - Departamento de Psicologia da Educação. Araraquara - SP - Brasil. 14800-901 - andreza_leao@yahoo.com.br

3 UNESP - Universidade Estadual Paulista. Faculdade de Ciências e Letras - Departamento de Psicologia da Educação. Araraquara - SP - Brasil. 14800-901. Coordenador do Núcleo de Estudos da Sexualidade (NUSEX) - paulorennes@fclar.unesp.br
} 
historicamente construído pela humanidade. Em linhas gerais, esta Instância social apresenta função específica, porquanto permite a assimilação do saber pelos cidadãos, saberes estes organizados no currículo.

Quanto ao currículo vale dizer que ele é um importante instrumento pedagógico. A necessidade de se compreendê-lo é por ele ser mais que um elemento educacional, como desvela Moreira (1997), ele é um importante componente social e cultural.

A palavra currículo denota a idéia do caminho a ser seguido para se alcançar os alvos do ensino, em outras palavras, as matérias que vão nortear e possibilitar aos alunos acesso ao saber da humanidade. Tal palavra é empregada desde os tempos da Grécia antiga, aonde emerge a concepção da educação promover a formação integral do homem. Nesta conjuntura histórica já se pensava em como sistematizar e organizar os conhecimentos que os alunos precisariam aprender (LEÃO, 2009).

A concepção de currículo remonta ao século XVI, mais precisamente na França, aonde se inicia a divisão precisa das classes escolares em grupos de aprendizagens. Neste contexto havia níveis de complexidade crescentes de conteúdo e conhecimento que seria exigido dos aprendizes. A bem da verdade, esta concepção sofreu modificações, as quais surgiram da necessidade administrativa de controle. Aproveitava-se, então, deste momento para se agrupar o alunado por idade e nível de conhecimento. Esta organização foi associada ao currículo prescrita e seqüenciada por estágios.

Este referido século tem como marco a ascensão calvinista, em que é possível notar uma relação homóloga entre currículo e disciplina. Deste modo, o currículo mantém relações com os padrões de organização e controles sociais, sendo confundido com disciplina, porquanto havia ênfase na disciplina nas escolas, sendo que a instrução ficava em segundo plano, sobretudo, porque a prioridade era a pontualidade e a ordem, relação está que se mantém até o século XIX.

A organização e o controle da escolarização no início do século XX são realizados pela Inglaterra, que transforma a educação escolar em uma atividade de massa subsidiada pelo Estado. É neste cenário que a classe e o currículo passam a integrar o discurso educacional. Não obstante, o currículo, como campo do conhecimento, surge somente nos anos 20 do século XX nos Estados Unidos (MOREIRA, 1992).

De fato, a partir de meados do século XX que acendeu o interesse no meio acadêmico com o conteúdo e com a natureza do conhecimento transmitido nas escolas. 
A partir de então, o currículo passou a ser considerado "[...] como um todo significativo, como um texto, como um instrumento privilegiado de construção de identidades e subjetividades." a fim de "[...] desenvolver os processos de conservação, transformação e renovação dos conhecimentos historicamente acumulados como para socializar as crianças e os jovens, segundo valores tidos como desejáveis pela sociedade." (MOREIRA, 1997, p.11).

Dentro da concepção histórica de currículo na atualidade, Libâneo, Oliveira e Toschi (2007) explicam que o currículo é uma forma de selecionar a cultura produzida pela sociedade para a formação dos alunos, é, além disso, tudo o que se espera que seja aprendido e ensinado na escola. Já Moreira (1997, p.12) discursa que ele é o "[...] conhecimento tratado pedagógica e didaticamente pela escola e que deve ser aprendido e aplicado pelo aluno." Para o autor, o currículo passa a significar o conjunto de experiências a serem vividas pelo estudante sob a orientação da escola.

O termo currículo só ganha evidência em território nacional com a primeira Lei de Diretrizes e Bases da Educação (nº 4024/61), sendo referido como a organização do conjunto de disciplinas a serem desenvolvidas nas escolas. Contudo, como relata Leão (2009), no referido documento não há uma discussão aprofundada acerca do currículo.

No tocante às disciplinas componentes do currículo escolar, elas foram (e ainda são) o resultado de um longo processo, não ocorrendo de forma desconexa e alheia ao contexto social, político, cultural e econômico da sociedade. Conforme explica Apple (1982), em sua obra intitulada "Ideologia e Currículo", o currículo não é indiferente ou desinteressado, uma vez que representa as estruturas econômicas e sociais mais amplas.

A despeito desta discussão, Santomé (1995, p.14) assevera que

[...] os projectos curriculares, os conteúdos do ensino, os materiais didácticos, os modelos organizacionais das escolas e liceus, as condutas dos alunos e do professorado, etc, não são algo que possamos contemplar como questões técnicas e neutrais, à margem das ideologias e do que acontece em outras dimensões da sociedade tais como a económica, a cultural e a política.

Silva (2006) argumenta que o currículo é um projeto da ação humana que não é nem tampouco será um produto acabado. Ele é, nas palavras do autor, um instrumento social e histórico, e como tal deve estar apto a ser constantemente debatido, interrogado e aprimorado, porquanto foi idealizado para realizar determinados objetivos 
característicos, ou seja, assegurar os privilégios e domínio dos que detêm o poder que buscam a todo custo a manutenção do status quo.

Moreira e Silva (1994) são consensuais em sustentar que o currículo não é um elemento neutro de transmissão desinteressado do conhecimento social. Com efeito, ele está implicado em relações de poder. Eles informam que o poder se manifesta nestas relações, isto é, em relações sociais em que certos indivíduos ou grupos estão submetidos ao anseio e ao arbítrio de outros. Assim, estes autores argumentam que

[...] apesar de seu aspecto contestado, o currículo, ao expressar essas relações de poder, ao se apresentar, no seu aspecto "oficial", como representação dos interesses do poder, constitui identidades individuais e sociais que ajudam a reforçar as relações de poder existentes, fazendo com que os grupos subjugados continuem subjugados. (MOREIRA E SILVA, 1994, p.29).

A esse respeito, Moreira (1997) complementa que os grupos dominantes tendem a afastar das salas de aulas os discursos dos grupos sociais explorados, como se inexistissem. Em linhas gerais, a escola na realidade produz e reproduz as desigualdades sociais (APLE, 1982).

Os currículos escolares foram organizados nos distintos contextos sociais. $\mathrm{Na}$ realidade esta organização se amoldou aos interesses dos que detém o poder, os quais determinam o que é válido e legítimo de ser transmitido (BRAGA, 2004).

Apple (1982) considera que o currículo não é somente o meio através do qual o conhecimento é caracterizado, classificado e hierarquizado, porém é, igualmente, o mecanismo através do qual os indivíduos são distinguidos, rotulados e hierarquizados.

A seleção curricular pode acontecer por dois caminhos: da transformação ou da reprodução. O primeiro deles busca sobrepujar o que já foi estabelecido em termos curriculares e busca incorporar elementos diferenciadores. Já o da reprodução, somente legitima o que é considerado normal e adequado, considerando que há um conhecimento válido e universal que deve ser ensinado aos alunos (BRAGA, 2004). Esta seleção do conteúdo a ser ensinado está condicionada a um sistema de controle, investido do poder de deliberar “[...] a divisão entre incluídos/excluídos, iguais/diferentes, normais/anormais, privilegiados/desprivilegiados. E, nessa lógica, apenas o normal, o igual, o privilegiado é incluído como conteúdo de ensino." (BRAGA, 2004, p.65). 
Destarte, o currículo formal que vigora nos dias contemporâneos, em que há fragmentação em diferentes matérias, atende as demandas da sociedade capitalista, criando os valores acolhidos como indispensáveis para o desenvolvimento da sociedade, estabelecendo a concepção de acumulação de conhecimentos, sem dar importância à reflexão.

Perante este quadro, Moreira (1992) propõe uma teoria crítica que inclua um redimensionamento da questão do conteúdo escolar e evidencie a rede de poder abarcada na determinação unidirecional do currículo e de um saber que vem sendo empregados para robustecer as disparidades existentes. Na opinião dele é preciso uma transformação radical do currículo, considerados os limites, as possibilidades e as peculiares das condições históricas.

Moreira (1997) e Libâneo, Oliveira e Toschi (2007) ressaltam que de fato há três tipos de currículos: o currículo formal, o currículo real e o currículo oculto. Como Libâneo, Oliveira e Toschi (2007, p.363) explicam, o primeiro deles, o oficial, é aquele estabelecido pelos sistemas de ensino expresso nas diretrizes curriculares e por meio dos PCNs. O currículo real, por sua vez, é o que ocorre na sala de aula em decorrência do projeto pedagógico e dos planos de ensino. Existe também o currículo oculto, refere-se às influências que comprometem a aprendizagem dos alunos e o trabalho dos professores, sendo originários "[...] da experiência cultural, dos valores e dos significados trazidos de seu meio social de origem e vivenciados no ambiente escolar." Esses autores corroboram esta distinção entre estes vários níveis de currículo, que servem para desvelar que o que os alunos aprendem ou não na escola depende de vários fatores, e não somente das disciplinas antevistas na grade curricular.

Do mesmo modo que há matérias que foram incluídos no currículo escolar, há conteúdos que foram excluídos, e não o compuseram. Embora eles não façam parte do currículo formal, eles rondam o ambiente escolar através de um conjunto de “[...] normas e valores que são implícitas, porém efetivamente transmitidos pelas escolas e que habitualmente não são mencionados [...] pelos professores." (APPLE, 1982, p.127). Estes conteúdos fazem parte do que se denomina de currículo oculto.

Santomé (1995, p.201) explica que o currículo oculto diz respeito aos

[...] conhecimentos, destrezas, atitudes e valores que se adquirem mediante a participação em processos de ensino e aprendizagem e, em geral, em todas as interacções que se dão no dia-a-dia das aulas e 
escolas. Estas aquisições, no entanto, nunca chegam a explicitar-se como metas educativas a conseguir de uma forma intencional.

O currículo oculto está presente na comunidade escolar no seu todo, porém ela geralmente não está alerta ou consciente da sua presença (SILVA, 2006), ao contrário do tradicional, nem sempre vai à direção de consolidação e legitimização dos interesses dos grupos sociais dominantes (SANTOMÉ, 1995). Na realidade é um subproduto do currículo formal, sendo decorrência da escolarização não presumida ou não aspirada de forma explícita. Está coligado aos comportamentos, aos valores e à prática didática dos professores, e muitos deles são inconscientes disso, e podem, ao contrário do currículo formal, incitar a reflexão.

Para Libâneo, Oliveira e Toschi (2007) o currículo oculto apesar de não aparecer no planejamento pedagógico ele se manifesta nas práticas e experiências na escola e na sala de aula, constituindo-se em importante fator de aprendizagem. De acordo com Moreira (1997), é transmitido implicitamente, tendo grande domínio no meio escolar, uma vez que pode propiciar controles sociais, lutas ideológicas e políticas, bem como, propor mudanças sociais. O mesmo autor em outro trabalho elucida que neste currículo incluem-se: “[...] rituais e práticas, relações hierárquicas e de poder, regras e procedimentos; características físicas do ambiente escolar; característica da natureza do agrupamento humano presente na escola; e, finalmente, mensagens implícitas no discurso do professor [...]" (MOREIRA, 1992, p.24).

Em relação à sexualidade, Braga (2004) considera que ela se faz presente no currículo oculto, enquanto seus conteúdos se escondem freqüentemente na linguagem naturalizada que produzem reproduzindo classificações e estereótipos. De fato, a sexualidade embora não esteja integrada aos componentes do currículo formal, está presente nos ditos e interditos escolares, na maneira de agir, articular e falar da comunidade escolar. Enfim, se manifesta e se expressa por meio do currículo oculto.

De acordo com Santomé (1995) não há uma consciência na esfera escolar da socialização sexista, isto é, o processo de construção das informações que vão definir a representação do feminino e masculino adequando os comportamentos das pessoas. Para esse autor "Pouco a pouco, a comunidade estudantil irá aprendendo quais as condutas permitidas e as proibidas, e em que momentos, bem como que significado deve atribuir-lhe a cada acontecimento, verbalização e objectos com os quais entra em contato no interior da escola." (SANTOMÉ, 1995, p.153). Embora não considere que 
haja passividade por parte dos alunos, ele afirma que vigora na escola um contrato didático na relação do professorado e aluno. Estes “[...] preocupam-se muito mais com aquilo que podem parecer aos olhos de seus docentes do que com a verdadeira finalidade da situação escolar." (SANTOMÉ, 1995, p.154).

Braga (2004) realça que, ao incorporar o tema da sexualidade no currículo formal, a escola arriscou-se a restringir todas as dimensões múltiplas da sexualidade a um único aspecto - o corpo biológico - expurgando outros. Esta não é a proposta dos PCNs, nos quais a sexualidade surge como um tema transversal em que, além de todas as disciplinas terem igual chance de abarcá-la, se explora o corpo, a afetividade e a questão de gênero. Entretanto, a citada autora lembra que é preciso considerar que muitas das ações educativas em sexualidade não ultrapassam os limites de ações provisórias.

Por isso é preciso frisar a necessidade de sua abrangência de forma permanente pela escola, uma vez que a sexualidade é um saber que deve ser tratado no currículo escolar. A proposta de inserção do tema transversal orientação sexual nos PCNs é uma tentativa de atenuar a lacuna de longa data no currículo sobre a abrangência desta temática.

Frente ao exposto, o presente estudo, de natureza qualitativa e quantitativa, teve por objetivo analisar a grade curricular do curso de Pedagogia de uma Universidade Estadual localizada no interior do Estado de São Paulo. Para tanto, foi realizado um estudo documental do referido curso, mas precisamente do seu processo curricular $\mathrm{n}^{\circ}$ 342/89, dos seus volumes I à IX, ou seja, do período que se estende de 1959 até 2009, bem como do programa curricular vigente até o ano de 2007. Além disso, empregou-se um questionário fechado contendo 20 questões o qual contou com a participação de 70 alunos de Pedagogia do período diurno e noturno da referida Universidade.

\section{Resultados e discussão}

O primeiro currículo deste curso, de 1959, apresentava um tronco comum de disciplinas e três especificações: Pesquisa, Administração Escolar e Magistério. Mas, nos seus quatro primeiros decênios de existência passou por várias alterações tendo em vista o seu ajustamento estruturado e formal. Inseriu e excluiu habilitações, estruturou e reestruturou a grade curricular, porém durante todo este processo não fez qualquer inserção do tema da sexualidade, salvo em 2001, quando por iniciativa do professor 
Paulo Rennes Marçal Ribeiro, docente do Departamento de Psicologia da Educação, foi oferecida a disciplina optativa 'Sexualidade humana e educação sexual', cujo objetivo era levar o aluno a compreender e assimilar os principais conceitos sobre sexualidade, e entender as diferenças e intersecções entre educação sexual e orientação sexual.

Além desta, foram oferecidas também as seguintes disciplinas optativas: 'Sexualidade humana, escolarização e atualidade: uma abordagem psicanalítica da educação/orientação sexual', 'Orientação sexual na escola' e 'Tópicos especiais em educação sexual: a função do orgasmo'. A primeira tinha por objetivo possibilitar aos alunos a realização de uma análise crítica das concepções dominantes de sexualidade a partir a psicanálise, e que fosse possível ao aluno examinar as modalidades de expressão de sexualidade tal como se apresentam na atualidade, em especial, na relação com a escolarização. A segunda objetivava fazer com que o aluno adquirisse elementos teóricos e práticos que lhes possibilitassem a desenvolver atividades de orientação sexual nas escolas, e Tópicos especiais em educação sexual: a função do orgasmo, tinha por intuito desenvolver no aluno a capacidade de compreender questões de sexualidade, como as disfunções sexuais e a função do orgasmo.

Estas disciplinas foram ministradas até o ano de 2004, sendo que não são mais oferecidas na grade curricular, e, nos processos do curso analisados não há qualquer justificativa para a inexistência de disciplinas do campo da sexualidade no curso.

As disciplinas da formação geral e dos eixos também foram analisadas e descritas. Em relação aos objetivos, conteúdos programáticos, bibliografias básicas e ementas, nenhuma delas aborda a sexualidade, ainda que algumas disciplinas componentes da formação geral dêem margem à discussão acerca deste tema:

- Estrutura e Funcionamento da Educação Básica, que tem por finalidade levar os alunos a compreenderem como se organiza e estrutura o sistema escolar brasileiro, de modo que possam, neste ínterim, compreender a legislação educacional contemporâneo. De maneira geral ela enfatiza temas que abrangem a cidadania, democracia, igualdade, cultura e o preconceito. Ela considera no conteúdo programático e na bibliografia básica a LDB 9394/1996, dando destaque a questão da educação para a cidadania.

Além disso, traz dois artigos na bibliografia, um que abarca os PCN e outro a sexualidade, são eles: Parâmetros Curriculares Nacionais: um discussão em abstrato, 1998 de autoria de Celestino Alves da Silva JR; e A escola e as diferenças sexuais, 1976, escrito por Fúlvia Rosemberg. 
- Educação Especial. Visa despertar a sensibilização do educador quanto ao seu papel de agente do processo de inclusão. Em sua bibliografia obrigatória recomenda a leitura de um livro que abrange a sexualidade, intitulado Educação especial $e$ estigma: corporeidade, sexualidade e expressão artística, de Manzini e Bracatti, 1999. Contudo, averiguando o citado livro constatou-se que ele apresenta somente um capítulo que abrange a sexualidade, sem se aprofundar neste assunto.

- História da Educação I. Dentre seus objetivos principais, almeja que os alunos adquiram habilidades e competências em história da educação, de modo a terem subsídios para melhor compreensão dos fenômenos educativos da atualidade. Um aspecto interessante desta disciplina é que propõe textos que discutam a família, a infância, a mulher, o casamento, bem como, o amor materno (sic), ou seja, assuntos estes que podem suscitar discussões sobre a sexualidade. Podemos inferir que havia a possibilidade desta disciplina trabalhar como se processou a história das mulheres, do amor materno, do casamento e da família moderna.

- História da Educação II. Seus objetivos são semelhantes à disciplina anterior, sendo que se caracteriza pela similaridade dos assuntos já tratados, isto é: criança, família, amor e mulher.

- Psicologia da Educação IV. Pretende que os alunos compreendam as relações da Psicologia, como um campo científico, com a educação escolar. Portanto, que eles possam relacionar as contribuições da Psicologia à prática pedagógica. Em síntese, ela objetiva o estudo do desenvolvimento da personalidade enfatizando a teoria psicanalítica. Dessa forma, no conteúdo programático apresenta que abarcará "os conceitos fundamentais do paradigma psicanalítico", bem como "as fases do desenvolvimento psicossexual". Na bibliografia básica foi possível constatar diferentes trabalhos de Freud, sendo eles: Totem e tabu (1974), Cinco lições de psicanálise (1978), Esboço de psicanálise (1978), O mal-estar na civilização (1978) e Interpretação dos sonhos $(\mathrm{s} / \mathrm{d})$.

- Teoria e Prática do Currículo. Tem por objetivo geral instrumentalizar os alunos para que possam realizar análises adequadas das propostas curriculares, e implementar ações para a difusão de inovação curricular. Apresenta em sua bibliografia básica os PCN, e devido a isso, pode ter apontado aos alunos as possibilidades, concretas de efetivarem estas inovações curriculares através dos temas transversais. 
No tocante ao eixo Formação de Professores para as Séries Iniciais do Ensino Fundamental, as seguintes disciplinas fizeram alguma menção a assuntos ligados à sexualidade:

- Desenvolvimento vocacional, identidade e escolarização. No conteúdo programático apresenta o papel da sublimação e na bibliografia básica sugere a leitura do livro Sexualidade na escola: alternativas teóricas e práticas, organizado por J. G. Aquino (1997).

- Educação Infantil. Embora busque promover o entendimento sobre o desenvolvimento da criança na Educação Infantil e nas Séries Iniciais do Ensino Fundamental, nada indica que trabalhe qualquer aspecto da sexualidade, mesmo dando espaço ao estudo dos PCNs.

- Linguagens em Educação. Esta disciplina contém no conteúdo programático uma unidade denominada corpo. A justificativa para isso é que ele é um instrumento passível de percepções, emoções, conhecimentos, que podem ser expressos com liberdade e prazer, através das distintas linguagens potenciais. Embora esta disciplina não esclareça o que seriam estas linguagens traz em seu conteúdo a discussão do corpo, mas não há qualquer menção à dimensão sexual do corpo.

Quanto ao eixo temático Formação de professores em educação especial, que a partir do ano de 2007 não foi mais oferecido, não foi possível fazer uma possível articulação com a sexualidade.

Não obstante, fazendo uma análise global destes programas de ensino nota-se que há parcas brechas para a inserção da sexualidade no currículo formal do curso de Pedagogia. Há menção dos PCN, o que pode significar que se possibilitou a abrangência deste assunto, porém não se pode afirmar que realmente isso tenha ocorrido. Do mesmo modo, as sugestões de leituras na bibliografia de artigos sobre este tema podem não ser acatadas pelos docentes responsáveis por estas disciplinas, ou ainda, elas podem servir apenas como textos de apoio.

Em suma, nos 52 anos de existência o foco deste curso esteve mais em adequálo às exigências do Ministério da Educação e do mercado de trabalho, desconsiderando alguns assuntos e questões que os discentes do curso de Pedagogia teriam de lidar na prática pedagógica com seus alunos. Nota-se a ênfase do curso nas disciplinas teóricas, sem possibilitar uma visão abrangente do contexto escolar, no qual o cotidiano de sala de aula exige do professor destreza e versatilidade para saber lidar com os alunos e com as diferentes indagações que estes apresentam. 
A sexualidade é uma das questões controversas presentes no cenário escolar, porém, o currículo oficial do curso de Pedagogia não lhe dá a devida importância. É como se fosse algo secundário e desnecessário de ser visto com os futuros educadores, o que contribui para perpetuação do estigma de que este assunto não deva ser abarcado, não sendo função de o professor atuar com questões de sexualidade (LEÃO, 2009).

Neste sentido, é pertinente averiguar se no currículo real, ou seja, naquilo que ocorre na sala de aula em decorrência do projeto pedagógico e dos planos de ensino (LIBÂNEO; OLIVEIRA; TOSCHI, 2007), há espaço para este assunto. Para tanto, investigar-se-á nas informações dos questionários elementos que demonstram ou não a abordagem da sexualidade.

O primeiro questionamento foi se os alunos achavam que há espaço em seu curso de graduação para a discussão de temas de sexualidade humana. Os resultados desta questão estão expostos no Gráfico 1.

Gráfico 1 - Espaço para a sexualidade na graduação

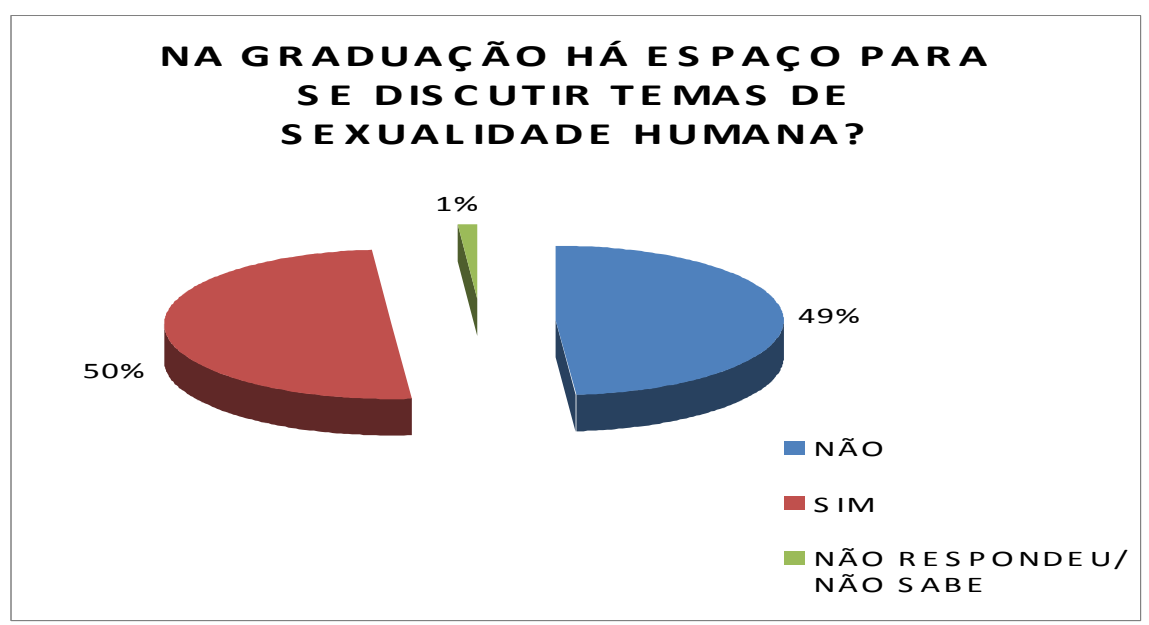

Fonte: Dados da pesquisa.

Como se pode notar no Gráfico 1, para 50\% dos respondentes, há espaços para discussão de temas relacionados à sexualidade, porém, 49\% disseram que não há espaço (um aluno não sabe ou não quis responder). Os sujeitos ficaram divididos, não havendo unanimidade de opinião.

Mas, se para metade dos participantes há espaço para discussão da sexualidade, é possível que esta percepção se deva a presença da sexualidade no currículo oculto. Segundo Libâneo, Oliveira e Toschi (2007), o currículo oculto embora não apareça no 
planejamento pedagógico se manifesta nas práticas do cotidiano escolar, constituindo-se em importante fator de aprendizagem.

Neste sentido, a questão seguinte indagou aos participantes que responderam sim qual foi o espaço onde houve a discussão destes temas. Os resultados obtidos nesta pergunta podem ser visualizados no Gráfico 2.

Gráfico 2 - Espaço que teve para discussão dos temas

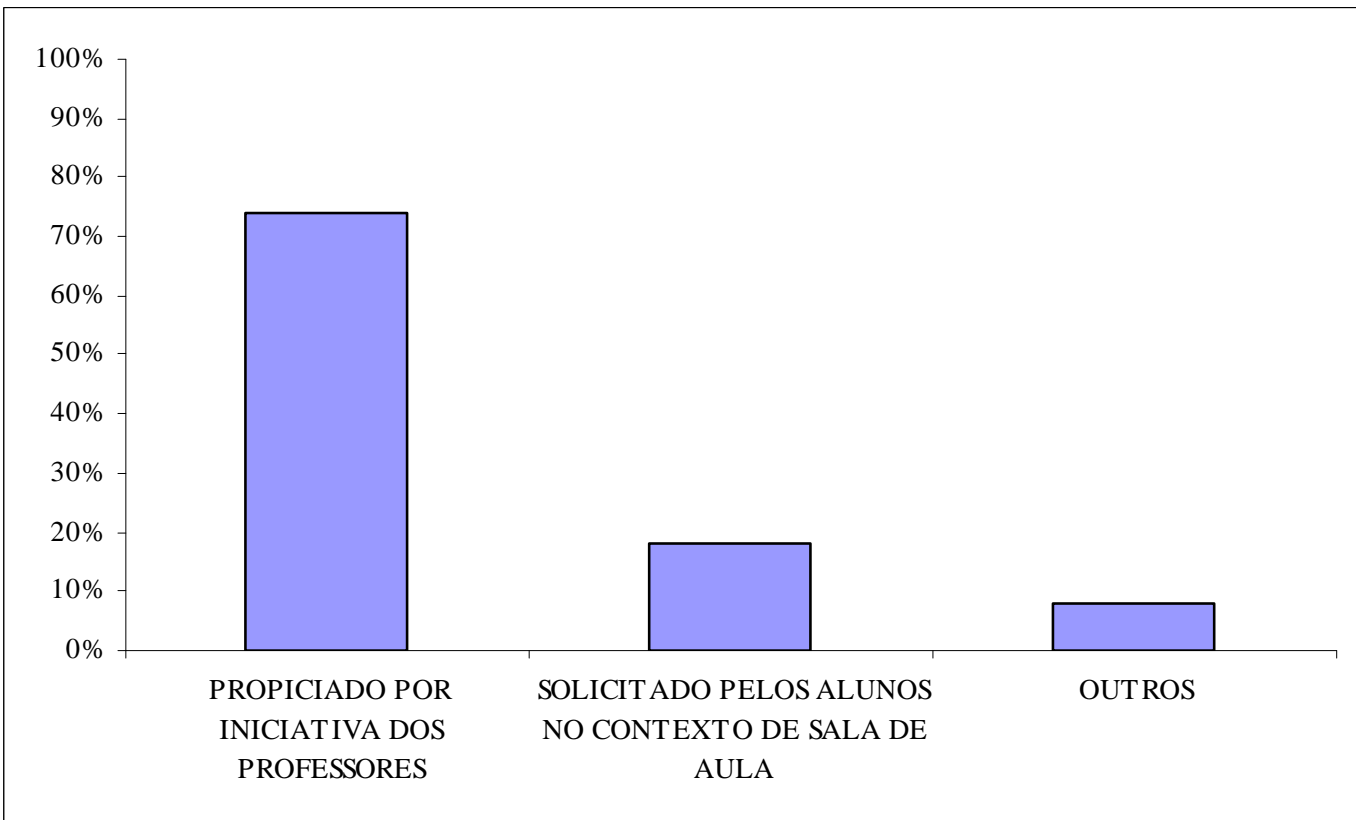

Fonte: Dados da pesquisa.

O Gráfico 2 revela que a discussão dos temas ocorreu principalmente por iniciativa dos professores ( $74 \%$ das respostas), mas que $17 \%$ dos sujeitos responderam que foi a partir da solicitação dos alunos no contexto de sala de aula. $9 \%$ apontaram outros fatores, como filmes, discussões ocorridas durante as aulas e oficinas de sexualidade infantil oferecidas pelo PET-Pedagogia. Muitos discentes disseram que estas discussões foram pontuais, ocorreram uma vez ou outra e não houve continuidade, o que desvela que este espaço foi restrito a algumas oportunidades ocasionais.

A questão seguinte investigou se o curso de graduação contribuiu para o conhecimento do aluno em sexualidade. Os dados obtidos encontram-se no Gráfico 3.

Gráfico 3 - Contribuição do Curso de Graduação no conhecimento em sexualidade 


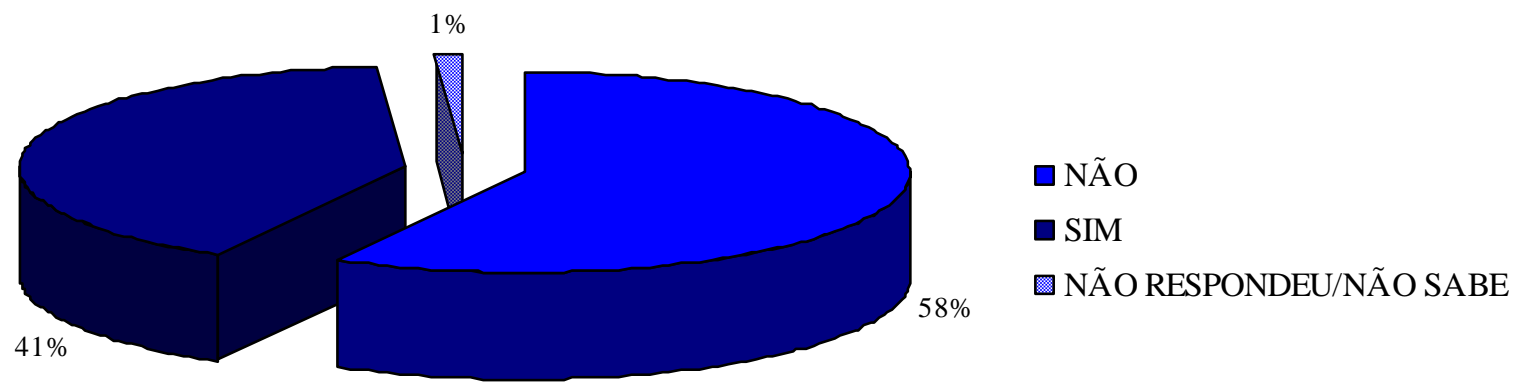

Fonte: Dados da pesquisa.

A maior parte dos respondentes (58\%) afirma que o curso de graduação não contribuiu para o conhecimento em sexualidade, mas podemos considerar que o percentual de $41 \%$ que afirma ter havido contribuição é um dado significativo.

Fizemos, ainda, as seguintes indagações: quais e em que sentido houve contribuições; como ocorreu; se os conhecimentos aos quais se referem os habilitaram a tratar questões de sexualidade em sala de aula; e, se não contribuiu, por que isso ocorreu.

De acordo com alguns participantes, o curso trouxe contribuições ao possibilitar o contato com este tema. Contudo, eles mencionaram que uma vez que isso ocorreu de forma superficial, breve e assistemática eles não se vêem devidamente instrumentalizados para abarcar este assunto no contexto escolar. Expressaram ainda que o ideal é que este assunto fosse tratado com mais profundidade e abrangência.

Os participantes foram interrogados se consideravam necessário que o professor tivesse conhecimentos sobre sexualidade. Os resultados obtidos quanto a esta pergunta estão expostos no Gráfico 4.

Gráfico 4 - Necessidade de conhecimentos acerca da sexualidade 


\section{VOCE CONSIDERA NECESSARIO O PROFESSOR \\ ADQUIRIR CONHECIMENTOS SOBRE \\ SEXUALIDADE?}

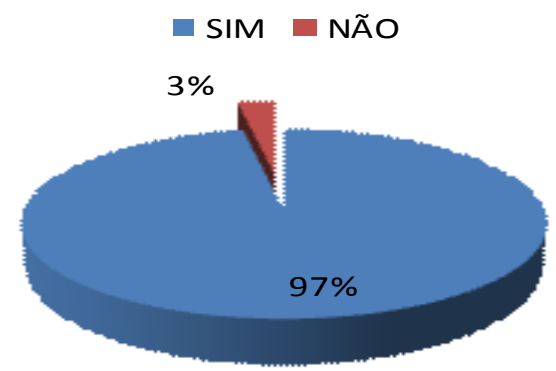

Fonte: Dados da pesquisa.

Analisando o Gráfico 4 pode-se constatar que a quase a totalidade dos participantes, ou seja, 97\% consideram que é necessário o professor adquirir este conhecimento, e apenas $3 \%$ dos respondentes consideraram desnecessário. As justificativas empregadas pelos participantes é que há uma lacuna na formação, e por esta razão devem adquirir conhecimento em sexualidade. Além disso, eles mencionam que o tema da sexualidade é de interesse dos alunos, suscita curiosidades, dúvidas e inquietações, e o professor é procurado para falar deste tema com eles.

Para abarcar este assunto eles precisam do conhecimento científico, pois é a forma de não transmitir aos alunos informação baseada no saber de senso comum, sem fundamentação científica, baseado na experiência imediata. De fato, o saber científico possibilita ir além, auxilia os professores a rever seus valores, a refletir sobre os mitos, tabus e preconceitos relativos à sexualidade.

Portanto, nota-se que embora a formação no curso de Pedagogia não oportunize aos discentes o contato com questões de sexualidade, eles sentem esta necessidade formativa. Ademais, revela que apesar da discussão em sexualidade ter surgido no contexto de sala de aula por meio do currículo oculto, sua incidência não foi suficiente para possibilitar uma formação aprofundada em sexualidade, mostrando que é preciso esta formação ser revista de maneira que o currículo real contemple efetivamente este tema.

\section{Considerações finais}


O currículo é importante instrumento, por meio do qual são delineados os aspectos principais a serem alcançados no contexto educacional. Ele pode ser real, isto é, ocorrer em sala de aula em decorrência do projeto pedagógico, bem como, ser oculto, sendo transmitido sem ser habitualmente mencionado pelos professores.

Analisando o citado curso de Pedagogia foi possível constatar as distintas alterações ocorridas no mesmo visando o seu aprimoramento. No entanto, desde o seu currículo inicial até o mais recente, inexiste espaço para disciplinas de sexualidade, sendo que o 'avanço' que pode ser assinalado é a introdução das escassas disciplinas optativas a partir de 2001, que não mais existem no curso vigente.

De fato, embora a sexualidade seja uma das questões controversas presentes no cenário escolar, o currículo oficial deste curso de Pedagogia não lhe dá a devida importância. Assim, ele fica à margem, podendo fazer presença somente por meio do currículo oculto. No entanto, seria viável que a sexualidade fizesse parte do currículo real, ou seja, constituir-se como disciplina, de maneira a se assegurar que seja realmente abrangida.

Cabe ao curso de Pedagogia a responsabilidade pela formação dos professores que irão atuar no ensino infantil e nas séries iniciais, níveis de ensino estes que formam crianças e adolescentes, geralmente carentes de informações de cunho sexual. $\mathrm{O}$ curso objeto deste estudo não tem como dar uma resposta eficaz ante a necessidade dos alunos, considerando que exclui a temática sexual, não provendo conhecimento desta natureza.

\section{SEXUALITY IN THE ABSENCE OF COURSE PEDAGOGY: THE HIDDEN CURRICULUM IN EVIDENCE}

ABSTRACT: The curriculum is an important instrument, through which are outlined the main aspects to be achieved in the educational context. It can be real, occurs in the classroom as a result of the education program, and be hidden normally be transmitted without being mentioned by teachers. Sexuality although it is not integrated with the components of the formal curriculum, and is present in said prohibited school, the way you act, speak and articulate the school community, expressing itself through the hidden curriculum. Considering this, the present study based on qualitative and quantitative aimed to analyze the curriculum of a course in pedagogy of a State University located in the State of São Paulo, as well as giving voice to students of that course in order to analyze if sexuality is to clearly present the formal curriculum. Therefore, a study of the documents in that course, but precisely its curriculum process $n^{\circ} 342 / 89$, their volumes I to IX, the period extending from 1959 to 200 , as well as the curriculum in force until the year 2007. In addition, we used a closed questionnaire 
containing 20 questions which included the participation of 70 students Pedagogy daytime and night of that educational institution. Since its initial curriculum to the latest nonexistent space for disciplines sexuality, and the 'progress 'that can be noted is the introduction of the limited elective courses that no longer exist in the current course. In the words of most students sexuality is not a matter encompassed in that course. These data show that both the real and the hidden curriculum does not give due importance to this issue. Therefore, it is imperative that this course, as well as the different undergraduate courses, should adhere to sexuality need to be part of the actual curriculum, in order to allow students access to this knowledge.

KEYWORDS: Curriculum. Sexuality. Sex education. Pedagogy.

\section{REFERÊNCIAS}

APPLE, M. O currículo oculto e a natureza do conflito. In: Ideologia e currículo. São Paulo: Brasiliense, 1982. p.125-157.

BRAGA, D. S. A sexualidade no currículo da escola fundamental: travessões e reticências sobre a homossexualidade nos discursos e nas atividades em uma escola municipal em Belo Horizonte. 2004. 156f. Dissertação (Mestrado em educação) Pontifícia Universidade Católica de Minas Gerais, Belo Horizonte, 2004.

LEÃO, A. M. C. Estudo analítico-descritivo do curso de Pedagogia da UNESP de Araraquara quanto à inserção das temáticas de sexualidade e orientação sexual na formação de seus alunos. 2009. 343f. Tese (Doutorado em Educação Escolar) Faculdade de Ciências e Letras, Universidade Estadual Paulista, Araraquara, 2009.

LIBÂNEO, J. C.; OLIVEIRA, J. F.; TOSCHI, M. S. Educação escolar: políticas, estrutura e organização. 4.ed. São Paulo: Cortez, 2007.

MOREIRA, A. F. B. Currículo: questões atuais. Campinas: Papirus, 1997. 1992. Currículo e controle social. Teoria \& Educação, Porto Alegre, n.2, p.12-27,

MOREIRA, A. F. B.; SILVA, T. T. Sociologia e teoria crítica do currículo: uma introdução. In: MOREIRA, A. F. B.; SILVA, T. T. (Org). Currículo, cultura e sociedade. São Paulo: Cortez, 1994. p.7- 37.

SANTOMÉ, J. T. O curriculum oculto. 3.ed. Porto: Porto Editora, 1995. (Coleção Escola e saberes).

SILVA, J. M. A pragmática comunicacional no currículo oculto: subsídios para uma abordagem interdisciplinar. Recensio: Revista de Recensões de Comunicação e Cultura, Portugal, 2006. Disponível em: <http://bocc.ubi.pt/pag/silva-jose-manuel-pragmaticacomunicacional.pdf $>$. Acesso em: 20 maio 2007. 